\title{
Sustainable E-Participation through participatory experiences in education
}

Participatory Culture, Political Education, ICTs, and New Media Literacy

\section{Ursula Maier-Rabler and Stefan Huber}

ICT\&S Center for Advanced Studies and Research in Information and Communication Technologies \& Society, University of Salzburg, Sigmund-Haffner-Gasse 18, A-5020 Salzburg, ursula.maier-rabler@sbg.ac.at, stefan.huber@sbg.ac.at, +43/(0) 662/8044-4801

\begin{abstract}
The understanding of participation as a political matter has changed back and forth over the years. The latest twist back to positive attitudes towards participation is fuelled by the development of the Internet, and especially the Social Web. Citizen participation is unanimously seen as an essential precondition for Deliberative-Collaborative eDemocracy (Petrik, 2010) enabled by Web 2.0. This paper considers participatory culture and its specific political, cultural, societal, and educational characteristics as a prerequisite for e-participation and argues that social media literacy is indispensable for eparticipation to be sustainable. Young people's affinity spaces (Jenkins, et.al., 2006) can only lay down the foundations for social media literacy, but their further development depends on education. Political Education would be well advised to adapt innovative pedagogical approaches to the acquirement of new media literacy. This paper introduces an exemplary educational tool - predominately but not exclusively for political/civic education - namely the website PoliPedia. at. Teachers can use it to deliberately create a balanced space for collaboration between Digital Immigrants and Digital Natives. PoliPedia - as a participative online tool - has the potential to facilitate participation experience in political/civic education and supports social media education. Thereby the embedding of technology in pedagogical and societal conceptualizations is crucial.
\end{abstract}

Keywords: e-participation, e-democracy, sustainability, participatory culture, political education, pedagogy, ICTs, new media literacy

Acknowledgement: The authors would like to thank Gudrun Haindlmaier and Sonja Einböck for their support as regards wording issues, as well as for generally proofreading the paper at its different stages.

$A^{0}$ bout 200 years after Jean-Jacques Rousseau had meaningfully placed individual participation at the centre of his political theory - describing the interrelationship between institutions, psychological qualities and individuals' attitudes - participation is still vital for democracy. But thinking on participation is far from uncontroversial. By the middle of the 20th century participation had become suspect because of the particularity of fascist and totalitarian regimes' (ab)use of participation (Pateman, 1970). Totalitarianism typically coerces people to participate in masses (Arendt, 1973) and in a homogeneous way. Democracy, in contrast, asks for the participation of the individual, offering heterogeneous ways for pursuing interests both on the level of personal wellbeing and the greater common good. Nevertheless, we have seen a steady decrease in voter turnout and party affiliation over the last decades (Putnam, 2000). The liberal stance typically highlights self-interested political actors who strive for private goals in a market-like arena, whereas communitarian traditions demand orientations according to the supposed common interests of a forum (Wiklung, 2005, 249). Once minority groups are competing with each other, but the citizenry is not actively participating in the policy-making, elite pluralism is in place (Bucy \& Gregson, 2001, p. 361). Nowadays, especially in the context of the Internet and Web 2.0, citizen participation is again seen as a key requirement for democracy and a lack of participation is considered a major threat to democracy (Lutz, 2006). Petrik (2010), for instance, outlines a new theory of deliberative- 
collaborative e-democracy based on citizen's participation enabled by Web 2.0. From a societal macro perspective, Fuchs and Obrist (2010) identify participation as a key-element for sustainability in current information society that allows integrated and interacting humans to selfdetermine their social systems. Likewise, Amartyr Sen's (2010) capability approach provides the basis for the conceptualization of an inclusive democracy, where the individual has a right to develop the necessary capabilities to be able to choose between different opportunities concerning his/her lifestyle. Especially these two approaches provide useful theoretic frames for conceptualizing new information and communications technologies (ICTS) and democracy.

This paper is going to focus mainly on the preconditions for sustainable societal and political participation. First, participation (considered valuable, even indispensable for democratically organized inclusive societies) is going to be addressed. Secondly, the prerequisites for the sustainability of Internet- and Social Web-based forms of participation - e-participation - are outlined in detail. Therefore, sustainability is defined as successful enfranchisement of present generations - without the disenfranchisement of future generations - to both take part in and influence agenda-setting and decision-making (Green \& Chambers, 2007). We refer to present and future generations, because we assume that today's agenda-setting and decision-making cannot be called sustainable if it limits future generation's decisional scope to undesired options. Additionally, in the context of e-participation, the generational issue has a second meaning: the differentiation between Digital Natives and Digital Immigrants (Prensky, 2001). Developing capabilities in using ICTs for societal participation is relevant for both of them and could serve as a facilitator for inclusive and therefore sustainable democracies. Furthermore, a close look at the characteristics of a participatory culture is taken. Subsequently, the importance of new media literacy in political education for sustainable participation is discussed. The online platform PoliPedia (www.polipedia.at) is introduced as an example to demonstrate the theoretical conceptualization of sustainable participation through participation experiences in education by the means of new technologies.

\section{E-Participation in the Context of Participatory Culture}

Political participation was typically defined as "direct citizen involvement in, or influence over, governmental processes" (Bucy \& and Gregson, 2001, p. 359). Modern e-participation seeks to empower people with the help of Information and Communication Technologies [ICTs], to enable them to integrate in bottom-up decision-making processes, and to develop social and political responsibility (Author et al, 2006). Many studies have found though, "that there is a mismatch between the requirements of democracy and most people's ability to meet these requirements" (Lupia \& McCuppin, 1998, p. 66). Meeting the requirements of democracy - making reasoned choices for instance - is based on people's deliberation and participation. The ways and tools facilitating widespread public exchange of arguments have changed significantly since Rousseau's times. Modern ICTs offer more possibilities to citizens when, where, how, and by which means they want to come to reasoned political choices. The ways of pursuing participation in society and politics have become ample. But this does not only leave citizens with a variety of participatory means at their hands, it poses major challenges to them too. If people want to move from occasional e-participation to sustainable e-participation, they need to learn how to make informed choices among the available ICTs and adequately use them. "[Media] Literacy is a matter of making sense, of constructing and communicating understandings in a world of great dissonance and great ambiguity, one which ICTs both create as well as help to resolve" (Mansell \& Avgerou \& Quah \& Silverstone, 2009, p. 19). Acquiring capabilities for the informed usage of social media is therefore at the heart of modern participatory society.

A participatory society is animated by its participatory culture.

"A participatory culture is a culture with relatively low barriers to artistic expression and civic engagement, strong support for creating and sharing one's creations, and some type of informal mentorship whereby what is known by the most experienced is passed along to novices. A 
participatory culture is also one in which members believe their contributions matter, and feel some degree of social connection with one another" (Jenkins \& Clinton \& Purushotma \& Robison \& Weigel, 2006, p. 3).

In this sense participation is more an attitude, a state of mind, a way of living, even a source of enjoyment than an abstract effort. Members of participatory cultures use ICTs for specific aspects, according to Jenkins et. al. they might establish new affiliations by becoming members of formal and informal online communities or produce new creative forms of art by which they express themselves. The preferred way of completing tasks in participatory cultures is collaborative problem-solving. By doing so, new knowledge is developed and made available. The mass media one-to-many mode is decreasing while circular and networked many-to-many modes of media distribution are increasing. As ICTs became more and more interactive, their adoption by society basically provides for a more participatory culture (Jenkins et al, 2006, p. 8). Although ICTs, and especially the collaborative Social Web applications currently being developed, have the potential to support societal and political participation, we must not forget that technologies can only facilitate the development of a participative culture, but they cannot trigger it by themselves. "Information and communication technologies are not the cause of social change but they provide the infrastructure to make the change possible as they offer the means of communication necessary for the formation of new forms of production, management, organization and globalization of economic activities." (Mesch, 2010, p. 2).

Similarly, the state of participation in any given society is not only a matter of political and technological conditions (cf. Skidmore \& Bound, 2008). The readiness of societies to actively encourage diverse ideas and to practice collaborative problem solving is deeply rooted in a general appreciation of transparency, openness, and sharing throughout society. Open and informationfriendly societies are more likely to develop a participatory culture than more or less hierarchical, information-restrictive cultures (Maier-Rabler, 2006).

\subsection{Two basic online environments of participatory culture}

\subsubsection{Virtual communities}

Theorizing participatory culture in the field of computer-mediated communication (CMC) started with the emergence of 'The Net'. The [Inter]Net is defined as loosely interconnected computer networks. They are considered an offspring from technological innovations made in the framework of American military research called ARPANET in the 1970s (Rheingold, 2000), conducted in close cooperation with academics. Howard Rheingold's work on the basic notions of cyberspace and virtual communities contributed fundamental categories to the research on information and communication technology and society. In his understanding, cyberspace is "the conceptual space where words, human relationships, data, wealth, and power are manifested by people using CMC technology" (Rheingold, 2000). When people commit themselves to "public discussions long enough, with sufficient human feeling, to form webs of personal relationships in cyberspace" (Rheingold, 2000), they form so-called virtual communities. In the late 1980s virtual communities like the WELL (the one Rheingold used himself to converse with friends and colleagues) were textonly environments. Still lacking today's huge variety of multi-media components, those early types of virtual communities allowed for the building of "relationships of startling intimacy" (Turner, 2005, p. 485). If people felt alienated by technology firsthand, the cyberspace opened up by computer networks helped them feel some kind of cooperative spirit. The new way of life those net pioneers were leading was composed by the "merger of knowledge capital, social capital and communion" (Turner, 2005, p. 486). From those days up until today, an uncountable number of virtual communities were established in virtually every corner of the world. They are essential elements of the participatory culture described above.

\subsubsection{Affinity spaces}

A participatory society, which involves its members on a large scale, requires educated and 
skilled citizens. Skills, which we prefer to refer to as media/ICT literacy, include the ability to access, navigate, critique, and create content by the means of information and communication technologies (Mansell, 2009, p.108). From a critical perspective, Mansell argues that people are increasingly dependent on such literacy and therefore we must be aware that media skills and literacy are not equally distributed within society. We argue that skills and competencies are developed comprehensively and socially balanced, if supported by the means participatory culture offers. Participatory culture, in its best form, represents an ideal learning environment. Whereas formal learning usually happens in schools, informal participatory learning takes place in affinity spaces, both offline and online in cyberspace. Affinity spaces serve as powerful opportunities for learning because "they are sustained by common endeavors that bridge differences in age, class, race, gender, and educational level, and because people can participate in various ways according to their skills and interests [...]" (Jenkins, 2006, p. 9). They are distinct from formal traditional education in that they are often experimental, innovative and dispose over provisional structures so that they can more easily respond to unprecedented needs. Besides reading, writing and calculating, formal education is teaching people the classical canon of education, but affinity spaces add social skills and cultural competencies on top. Active involvement in online affinity spaces is a form of online participatory culture. According to Kann, Berry, Gant and Zager (2007) online participatory culture's potential to increase involvement in public life is multifaceted: first, values conducive to democracy, such as openness, honesty and vigilance against tyranny, are promoted. For example, Video the Vote (http://videothevote.org), whose members document disenfranchised voters and faulty voting machines on video, posting them immediately on YouTube. Second, involvement in online participatory culture augments citizenship skills. Knowing about alternative political approaches, which could also be different from one's own, supports the development of capabilities, which Sen $(1999,2009)$ defines as acquired cognitive capacities and the ability to discriminate between alternative choices. People's exposure to dissentient political information and ideas, which is generally the case when actively involved in participatory culture, demands for skills and literacy which enables them to asses, choose, and create information and digital content. Online games can be affinity spaces too when the players cooperate to solve problems in a fictional world and thereby learn to apply their knowledge about collaboration to political problem-solving in the real world. Third, social networking sites support people to organize themselves in affinity groups by which political mobilization is facilitated. Nevertheless Kann et al. (2007) admit that virtual space is not equivalent to actual space and digital democracy therefore "amounts to very little without manifestations of political activism" in public life.

\section{E-Democracy Needs Political Education to Foster E-Participation}

Early radical and rather techno-deterministic concepts of e-democracy theorized "a total transfer of power from elites to plebiscitary publics" (Coleman, 2007, p. 375). In stark contrast to such modernist agendas, recent research on e-government concludes "that digital technologies are used to reinforce existing organizational arrangements and power distributions rather than to change them" (Margetts, 2009, p. 117). E-democracy initiatives run by government, which turn out to be rather e-government initiatives instead, rarely aim at citizen empowerment as much as civil society organizations would like. A study on local e-government solutions in Sweden attested egovernment to go beyond processes of deliberation but stay behind aspirations of digital democracy. The ICT-enabled services investigated by the study represented only marginal supplements to established political institutions (Wiklung, 2005). In fact, a number of e-government conceptions seem to shy away from power transfer but reveal a

"growing unease among political elites about the unsustainability of indirect representative structures and processes and the need to mediate the relationship between representatives and represented in ways that can reconcile the democratic benefits of participation and the institutional complexities of governance" (Coleman, 2007, p. 375). 
Citizens lack trust in governmental top-down e-democracy initiatives, partly because they feature "too close an alignment with governmental requirements rather than citizens' needs" (Maier \& Reimer, 2010, p. 47). This is also a result of the mix-up of e-democracy and e-government. Most of the so-called e-democracy initiatives are actually government-driven e-government initiatives, which first and foremost target for rationalization of bureaucracy and only secondly aim for the involved and capable citizens. Petrik's understanding of e-democracy goes further than most of the existing e-democracy initiatives. It seeks to involve both governmental and non-governmental actors in a continuous process of joint deliberation and collaboration on policy issues (Petrik, 2010, p. 19). Although being only moderately empowering, his approach puts high demands on citizens' social media skills: the manifold features of e-democracy platforms that citizens are meant to master comprise systems of suggesting policy issues, forming lobbying groups and developing concise policies on wiki servers. Deliberating on these issues in discussion forums, evaluating them mutually, and finally making decisions are further comprehensive tasks citizens are thought to come to terms with, partly directly or using distinct proxy representation systems for delegation (Petrik, 2010, p. 21). The Social Web is not merely a solution to democratic questions; it is a challenge in itself. In its Digital Agenda, the European Commission (2010) intends "to foster digital literacy among citizen[s]" and calls digital competence a key competence of individuals in a knowledge-based society. The requirements of Web 2.0 based democracy extend the list of capabilities citizens are supposed to have in order to participate actively in democratic processes. Also before the society-wide diffusion of the Internet, political involvement was higher among people of high formal education or salary (Escher, 2010). The new information and communication technologies did not (yet) significantly narrow this gap, and without targeted political and educational policies, they never will. For easing the political participation gap by the means of the Internet and the Social Web, closing the digital divide between the social media literate and illiterate must be an equally important goal. If e-democracy policies attempt to enrich and support civic participation, the individual citizen has to be empowered to a maximum in his/her ability to participate in the democratic process.

Citizen participation in democratic processes has two indispensable prerequisites: individual interest and opinion formation (Author et al, 2007). Access to information in the first place is the main argument for praising new information and communication technologies as enabler for citizen participation and therefore more democracy. Additionally, we already know that access alone is not enough and that people need to acquire skills and literacy in order to retrieve the pursued information. Little attention is paid to the missing link between access and literacy, which is motivation and interest for - in this case - political/civic engagement. In ICT-based affinity spaces, people learn to handle new technologies and social media. To actually encourage (young) people to use the newly acquired skills for participatory purposes, further motivation and guidance is needed. The integration of the up to now separated spheres of formal education in school and informal (ICT-)learning in affinity spaces could support the development of motivation for civic and political engagement. Citizens and users usually do not take significant effort in screening offline and online sources on subjects they are not interested in firsthand, but using skills they learnt in their respective affinity spaces can be a starting point for motivation. Empowering youth by directing their new media literacy from the informal learning environments of the affinity spaces towards formal learning space in schools could become a point of departure for a modern civic/political education. Additionally, this approach spans over generations in the sense of sustainability and gives teachers and pupils a balanced role in future, collaborative learning.

Krammer (2008, p. 5) defines the aim of political education as empowering youth to acquire competencies that allow them to develop and maintain self-determined political thinking as well as to participate actively in political processes on their own initiative. In his model of self-reflexive political consciousness, political education is successful, if pupils learn to evaluate divergent political opinions and form their own reasoned choices, based on knowledge; permanently mentally ready to change their position on a policy issue if new facts become available. The actual level of political competence a pupil attains at a certain age depends massively on out-of-school variables, 
such as family orientation, peer socialization and learning opportunities among friends and acquaintances (Kramer, 2008, p. 12-14). Affinity spaces represent ideal informal learning spaces, which should be connected to the formal educational sphere and beyond. The co-operative character of the Social Web could support the exchange between peers, within school and even beyond schools. By providing additional web-based affinity spaces, pupils and adult citizens alike are offered further opportunities to strengthen their socio-cultural skills and political competencies needed to face the challenges of active citizenship in Web 2.0 supported democracies.

Yet the British Department on Constitutional Affairs expressed concern about possible negative effects of virtual communities on social cohesion:

"Whilst virtual communities might offer new opportunities for active citizenship, it is likely that as they focus narrowly on interests shared by certain segments of the population - individuals might disengage from shared responsibilities, obligations and duties toward fellow citizens and the state." (Department of Constitutional Affairs, 2007, p. 40)

Hence, it is important that democratic institutions offer opportunities to apply social media skills and political competencies learnt in any kind of virtual community by connecting to the affinity spaces of their citizens and constituents. If, for example, people produce videos reporting on their sports activities (a popular affinity space) and put them on YouTube to share with their friends, it is likely that their video skills will be sooner or later adopted for reporting on broader civic or political matters. It will then be the responsibility of formal political education to engage with the technologically experienced young citizens in these connected affinity spaces in order to trigger motivation and provide participation experience. Attempts to motivate young people for individual participation in democratic processes oblige democracies to offer experiences and opportunities. A new ICT-based chance for political education to be successful in creating initial interest in policies among pupils is to attract pupils' attention by appreciating and drawing on their media skills learnt in their respective affinity spaces. Trans-institutional group work on environmental protection policies, for instance, can be much more enthralling if it involves making videos on failed or exemplary environmental protection in the neighborhoods, putting the videos online, getting the local media's attention, encouraging politicians and the public in getting the site cleaned in a collective effort, or educating interested groups about this matter. Afterwards, theory on participatory democracy can be easily reflected in retrospectively in class. Political education can and must be more than learning the political history of one's country by heart.

Another approach towards political education would be to raise pupils' initial interest in certain policies or politics in general by applying high rates of interactivity. Results of political education that make it into cyberspace by the production of text elements, audio or video files - that do not vanish in the teacher's cabinet - not only enhance the commitment of pupils, but trigger reactions of fellow pupils across school and beyond as well. As already mentioned, Social Web based political education unites teachers and pupils alike in joint affinity spaces to cooperate beyond school, and beyond top-down curricula. Learning about migration policies by providing secondary information through e.g. textbooks can be a starting point, but should not be the end of all means, since social media offer more interesting and direct testimonies of people concerned. A paper print textbook which has received approval by numerous committees before becoming a textbook for political education in schools can provide basic knowledge, but does not involve the pupils and does not make them individually involved. Self-made and self-experienced content is a necessary supplement and enrichment of regular learning material in schools in the age of Social Web. Multimedia components produced e.g. on wiki platforms will make learning a more participatory process. Once interviews with authentic immigrants on migration policies are put online, commented by others, discussed in class and reflected by the interviewers, pupils will gather significantly more experience with the subject matter and become sensitive for any developments in the future of the policy field. Social media platforms have the potential to change the nature of education by producing as well as consuming multi-media components. The characterizing aspect of such prosumers (Toffler, 1980; Tapscott, 1995) is a high degree of self-determination, as 
opposed to the preceding generations of tv-kids (Beisswenger, 2010; Paus-Hasebrink, 2004). Integrating the participatory potential of the Social Web into formal education challenges the whole system. Teacher- pupil-hierarchies are questioned and the agents of the educational system are not "in possession of the only truth" anymore. Realizing a balanced relationship between teachers and pupils in acknowledging pupils' ICT skills acquired in informal affinity spaces as well as teachers' competencies in evaluating, structuring, and applying content for educational reasons could be the first step towards participatory education, an essential precondition for sustainable eparticipation.

In 2008 the Austrian Federal Ministry for Education, Arts and Culture enacted new regulations on political education (2008, Regulation Nr. 290). Embedded in the subject of "Geschichte und Sozialkunde/Politische Bildung" (i.e. History and Social Studies/Political Education), the didactic approach to be applied henceforth is based on a model of four key competencies. The educational goal represented in the model is to empower pupils with the competence to take reasoned decisions based on sound judgment (Politische Urteilskompetenz), participate in political problemsolving (Politische Handlungskompetenz) choose among methods for analyzing divergent political angles and articulating one's own attitude in a discursive manner (Politische Methodenkompetenz) and, finally, to understand political notions and categories (Politische Sachkompetenz). Teachers are asked to choose topics according to the model. The change of priorities in the Ministries' regulation, turning away from the content of the curriculum, but focusing on competencies, is a major challenge in teaching (Ammerer und Kühberger, 2009, p. 31). On the one hand, the curriculum stipulates compulsory topics to teach at specific levels of education. On the other hand, as Ammerer and Kühberger point out; it leaves teachers with the freedom to carefully weigh the time spent on them (2009, p. 32). This requires each teacher to consider the competencies s/he wants to be developed via a specific topic. In practice, a limited number of case studies can be conducted thoroughly, while some topics can merely be glanced at. From time to time it can be necessary to calculate several lessons for in-depth investigations or to carefully choose specific methods and media useful for the development of certain competencies. In order to facilitate the necessary political analysis and discursive skills, even more teaching time must be dedicated to new media.

\section{New Media Literacy Skills as Part of Political Education}

\subsection{PoliPedia as a participatory tool in political education}

When the legal age for voting in federal elections was lowered from 18 to 16 years in Austria in 2007, the Federal Ministry for Education, Arts and Culture and the Ministry of Science and Research jointly launched a corresponding package of measures, the so-called Austrian Democracy-Initiative. The intention of the initiative was to quicken youth's interests for politics and democracy. One of the projects initiated was an innovative Web 2.0 platform. A wiki-based tool, called PoliPedia, was used for the collaborative production of an online textbook for political education by pupils, teachers, and interested individuals alike. The functionality of the wiki-tool is further enhanced by three features: entries can be enriched by multimedia components, commented on, and assigned with tags (Banfield-Mumb \& Mayrhofer, 2010). The aims of the project were to strengthen participative skills, create space for user generated content, enhance the availability of information about politics, and to foster collaborative knowledge production and political online participation. This bulk of aims could be fulfilled by collaborative text production: by now, PoliPedia offers a wide variety of topics, ranging from various theoretical approaches to democracy, over specific policy fields to special foci. Although this example of using social software for political education is successful in text production, it is facing a number of problems. While pupils are sometimes limited in voicing their ideas due to lacking skills in written expression, technophobe teachers ignore some opportunities offered by social software (e.g. creating and adding multimedia components, commenting on entries, or assigning tags) right away. Further on, the absence of awareness of concepts like copyright and privacy is still widespread among pupils. 
In the context of audiovisual content, students show high skills compared to their teachers, which questions the traditional power relationship between pupils and teachers. It is important to note though, that the expert status young people hold in the eyes of parents and teachers is largely based on their technical skills. This does not suggest that they possess media capabilities (Sen, 1999). Knowing how to apply one's ICT skills to the process of democracy is nothing innate. From this perspective, young people's competencies to use new media for participatory actions are alarmingly deficient (Diendorfer \& Maier-Rabler \& Parycek, 2010, p. 235). If teachers want to equip pupils with the media literacy needed for political participation, they can either struggle to catch up with the technological skills of their pupils, or create a balanced space for collaboration that allows them to learn from each other. This makes clear that the dominating problem in incorporating new information and communication technologies into the education system and especially into political education in order to enhance the development of a participatory culture is neither a technological nor a didactic one. It challenges the traditional hierarchies in the educational system and requires new settings regarding the role of teachers and new answers to the question of who is in possession of the truth. Teachers need to adopt a positive attitude towards mutually benefiting collaboration with pupils. Therefore training on how to teach the efficient use of available online tools is needed for teachers.

What does a balanced space for collaboration of teachers and pupils in the field of social software for political participation look like? Setting up balanced spaces for collaboration intends to counteract the contemporary separation of traditional competencies from innovative competencies. Rheingold (2006) argues that

"[e]ducation - the means by which young people learn the skills necessary to succeed in their place and time - is diverging from schooling. Media-literacy-wise, education is happening now after school and on weekends and when the teacher isn't looking, in the SMS messages, MySpace pages, blog posts, podcasts, videoblogs that technology-equipped digital natives exchange among themselves." (Reingold, 2006)

In the sense of balance, pupils bring in their media skills acquired in their respective affinity spaces and pass them on to their teachers e.g. regarding the production of content. Teachers, on the other hand, bring in their traditional skills, values and judgment in order to enrich pupils' production quality-wise and guide them on aspects in reference to the subject taught. The common goal of teachers and pupils is to contribute their knowledge to the collaborative learning environment, rather than competing with each other. In the case of political education, teachers can use PoliPedia to deliberately create a balanced space for collaboration. Within the walls of the classroom they can collaboratively produce audiovisual or text content with their pupils and post it online. In a further effort, teachers can cooperate with fellow teachers working at different schools, collaboratively giving feed-back to other classes' contributions. Both quantity and quality of pupils' multimedia output will increase, and the attained intensive level of participation can be considered as preparation for real political and societal participation outside school. Besides, PoliPedia contributes to the establishment of a participatory culture by fostering respect and appreciation of the opinions and contribution of others, collaboratively piling up a common body of knowledge in the field of the political for educational purposes.

Simulation games are a useful tool in preparing pupils for real live situations. Windischbauer has developed several of them, including one about election procedures (2008). The basic idea of her simulation game "Wie wird gewählt?" (i.e. How to vote?) is to substitute pupils' active operating experience for teachers' abstract explanations about election procedures. Supervised by their teacher, the pupils learn how to vote by organizing, conducting and evaluating a fictional parliament election. Made to measure for 16-year-olds, the simulation game enhances teenagers election competence and reduces the risk of non-voting due to nescience, ambiguity and fear. Similar to simulation games, PoliPedia can be applied by teachers in collaborative learning. Disregarding whether democracy as a whole or a specific policy field is intended to be approached, PoliPedia is a tool that allows pupils to collaboratively work on any political subject matter and participate in the 
development of an online multimedia wiki for political education. The active experience of collaboration on PoliPedia can be just as much a preparation for political and societal participation as a simulation game on elections can be training for voting on election-day. What still needs to be done to facilitate teachers' application of PoliPedia in class, is to develop guidelines on how to incorporate such a collaborative tool in tuition.

Diendorfer and Mayrhofer (2009) outline a scheme of how the participatory use of new media in political education could be structured with PoliPedia. For demonstration purposes they choose the topic of human rights, scheduled in curricula from the $7^{\text {th }}$ to the $12^{\text {th }}$ grade. The higher the level of education, the more complex and comprehensive the questions pupils are asked to work on. For instance, in lower classes, pupils will start with simple online search, in higher classes pupils are asked to distinguish between human rights, basic rights, and civil rights. In the first of four lessons planned for the project, every single pupil registers anonymously on the wiki-platform of PoliPedia. The teacher assigns the task: adequately putting their findings on human rights online on PoliPedia. This requires pointing out the rules of Netiquette on quoting sources and trustworthiness. Pupils then start working together. They brainstorm and draw mind maps. In the second lesson, groups of pupils are formed that will search the net for answers. This involves teachers' input on how to search, quote, evaluate accuracy and save intermediate data by printing, copying or resuming. Two more lessons are used for publishing the information gathered by writing collaboratively on PoliPedia's wiki-articles. Any testimony of the working process - i.e. pictures of pupils discussing questions or presenting results, digitally photographed mind maps, or examples of questionnaires - can be uploaded to PoliPedia's storytelling-blog. At the end of the fourth lesson, the class critically reflects its experiences with target-oriented collaboration supported by new social media.

\subsection{Educational methods for the development of new media literacy}

Both the playful use of social media young people exercise in their affinity spaces and the collaboration based on Web 2.0 they are performing at school when working with PoliPedia are contributing to the development of the civic competencies deliberative-collaborative eDemocracies (Petrik, 2010) require from citizens. The great efforts of the 1990s in providing access to the Internet did not miraculously equip people with the competencies for societal involvement. Mere access to ICTs was not enough. Just as cars would not have transformed mobility, if people had not learnt how to drive. "The fact that citizens rarely use the Internet for political purposes manifests that access to means of communication is not enough; it illustrates the importance of motivation, that citizens find reasons to use the infrastructure" (Wiklung, 2005, 262). Without citizens competently applying social media, the effect of their participation in society and policy-making does not change significantly, even if technology is available. Being a new kind of media infrastructure, the Internet demands not only motivation but new media literacy, if e-participation is to be sustainable. For Livingstone, literacy "emerges from the interactions among a motivated and skilled individual, a well-resourced socio-cultural context and a well-designed interface" (2009, p. 501). Jenkins et al. name eleven "core social skills and cultural competencies that young people should acquire if they are to be full, active, creative, and ethical participants in this emerging participatory culture" (2006, p. 56). The paper at hand suggests that affinity spaces can lay down their foundations, but some of them can be developed considerably further if schooling applies proper means of education (Rheingold, 2006).

The capacity to experiment with one's own surroundings as a form of problem-solving as well as the ability to adopt alternative identities for the purpose of improvisation and discovery - Jenkins' respective definitions for Play and Performance - are typically thought to play major parts in children's lives. But a child does not need to attend school in order to learn how to play or perform; elements of play and performance should be enriching childrens' learning experience at school. The ability to interpret and construct dynamic models of real world - Simulation - has further become a respective educational method, sometimes applied in elaborate simulation games. Appropriation means the ability to meaningfully sample and remix media content. When working on 
an article on PoliPedia or making a video illustrating an article, pupils draw on the cultural reservoir they know and analyze the existing content. Their creative remixing of cultural productions is a process of active commenting, as opposed to mere exposure. If they use different media channels to pool information about a story they want to comment on (e.g. written articles, audio podcasts, videos sequences), or tell their own point of view using various media channels, pupils train their skills in Transmedia Navigation: the ability to deal with the flow of stories and information across multiple modalities. Searching various sources for information, synthesizing and disseminating it is called Networking. Networking skills can be trained in the framework of PoliPedia by using webquests ${ }^{1}$ helping pupils to structure difficult topics. Related with Networking is the topic of Judgement, defined by Jenkins as the ability to evaluate the reliability and credibility of different information sources. A recent survey among Austrian pupils revealed very little consciousness among digital natives about what concerns diversity and quality of online sources (Diendorfer \& Maier-Rabler \& Parycek, 2010).

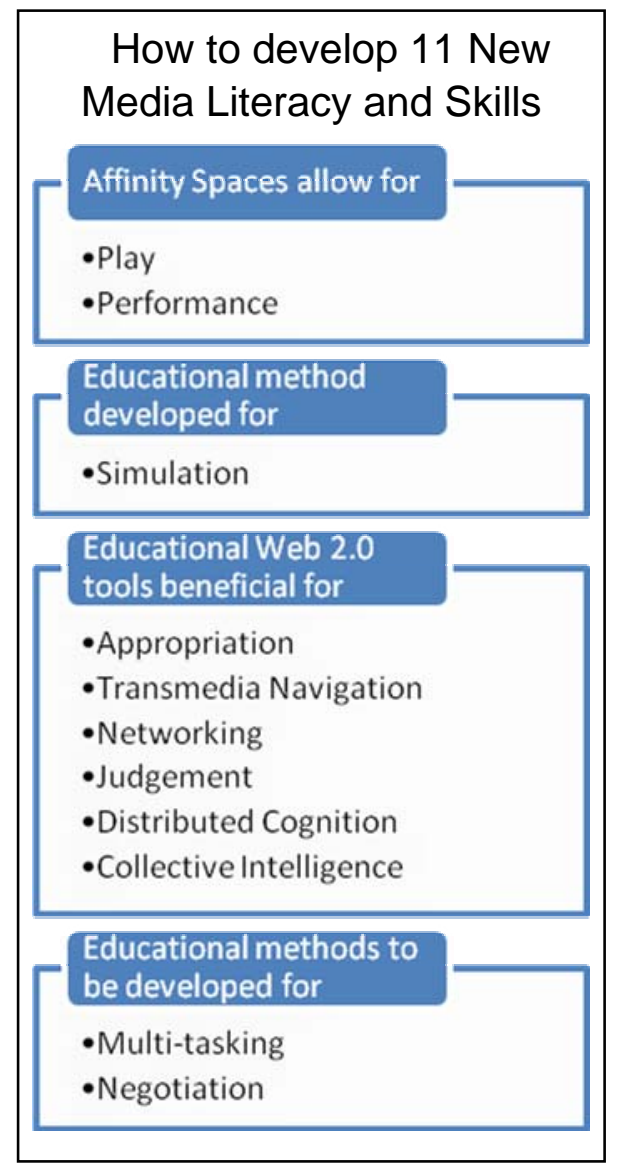

Figure 1: categories for the development of new media literacy. Contains 11 skills according to Jenkins, 2006

Working on a wiki-article on PoliPedia requires constant evaluation of the sources cited. This gives teachers - typically digital immigrants concerned by diversity and quality of sources - the opportunity to point out the importance of reliability and credibility when learning about Distributed Cognition. The latter is the term used for the ability to interact meaningfully with tools that expand our mental capacities. Just like a calculator expands our mathematical capacities, wikis for instance expand our mental collaboration capacities. Wikis and other tools are useful when creating

\footnotetext{
${ }^{1}$ i.e.: "activities designed by teachers ,in which some or all of the information that learners interact with comes from resources on the Internet' (Dodge, 1997)" (Jenkins et al, 2006, p. 50)
} 
Collective Intelligence: the ability to pool knowledge and compare notes with others to reach a common goal. If, for example, groups of pupils in remote classrooms collaboratively work on an article using the PoliPedia wiki, they produce collective intelligence. Further new media literacy skills that call for pedagogical approaches are Multi-tasking and Negotiation. The former stands for the ability to scan one's environment and shift focus onto salient details on an ad hoc basis. The latter is a cultural capacity. Within new media environments culture flows between communities. Negotiation signifies the ability to travel across diverse communities, discerning and respecting multiple perspectives, and grasping and following alternative sets of norms (Jenkins et al, 2006, p. 52). None of the new tools or applications available can take on such a comprehensive cultural challenge. A set of methods has to be developed that allow educators to "foster negotiation skills when they bring together groups from diverse backgrounds and provide them with resources and processes that insure careful listening and deeper communication" (Jenkins et al, 2006, p. 53). Nevertheless, the development of six out of eleven core new media skills can be supported by the pedagogical use of Web 2.0 tools like PoliPedia.

\section{Conclusions: Prerequisites for Sustainable E-Participation}

Due to the changing nature of 'participation' resulting from ongoing developments in politics, society, media and ICTs, prior reservations about participation gave way to aspirations of citizen participation in society and policy-making. 'Participation', understood as individual involvement and engagement in broader societal, political and civic matters gained momentum in the last third of the $20^{\text {th }}$ century in the course of big environmental (e.g. anti-pollution, anti-nuclear power) and social (e.g. peace, feminism) movements. The Internet has been a supportive facilitator of those movements in the 1970s and 80s (e.g. the early networks like peacenet, greennet, and econet). With the emerging Social Web in the 1990s and the beginning development of so-called Web 2.0 technologies in the mid 2010s, the successful utilization of online technologies became a matter of (e-)participation at the existing and emerging network society (Castells, 2000). The omnipresence of participative network technologies (e.g. social media like Facebook, YouTube, Flickr, peer-topeer networks and Web 2.0 tools like tagging, wikis and blogs) now challenges official democratic institutions and traditional political and societal organizations, like parties, churches, unions, etc.

The generation of the Digital Natives is firm in using and applying all those technologies for their immediate expression. But besides technological skills, sustainable e-participation needs media literacy. There is a need to equip both Digital Immigrants and Digital Natives with the media literacy and cultural competencies required to become full participants in an emergent media landscape and raise public understanding about what it means to be literate in a globally interconnected, multicultural world. One approach to address the crisis of democratic institutions and socio-political organizations is, besides many others, by the very means of new information and communication technologies (ICTs) and benefit from the participatory potential of New Media for democratic purposes. In this paper we give an example of Social Web technologies creating real participation experiences in school, establishing a balanced and trustful learning environment, and educating future citizens in basic democratic principles. By integrating social media into the core of formal education, i.e. teaching and learning in the classroom, in a way that allows teachers and pupils to interact with each other in a balanced and participatory fashion, we are likely to raise pupils' motivation to get into subjects outside of their core interests. Especially the subject of political education could benefit from a participative teaching style, which respects the skills and everyday social experiences of the pupils.

The social media tool PoliPedia is introduced as a wiki-based tool for political education (and beyond). Teachers and students collaboratively contribute to a body of knowledge concerning the subject, sharing their work with other classes, both within and beyond school. Such a way of collaborative learning requires the creation and exchange of skills and literacy on both sides. Pupils need to learn how to apply their everyday media to learning about serious matters in school. Teachers on the other hand must be affirmed that they can help them doing this, even if they are not experts in the latest Web 2.0 technology. This leaves also space for guided facilitation by older 
teachers. They can rely on their expertise on the subjects treated, but must be open for the expertise of the children regarding the use of technology.

We think it is uncontroversial to suppose that pupils who have positive experiences with participation and, more specifically, with a participatory culture at school (i.e. space to express one's opinion, being taken seriously, experiencing a supportive environment for one's creativity), are better equipped to develop a democratic-participative lifestyle than they would be within a traditional, hierarchical, top-down system of formal education. If the resistance to social media applications in formal education, and more generally the resistance to a balanced relationship in learning environments, are overcome, PoliPedia could become a tool for sustainable eparticipation.

\section{References}

Ammerer, H., \& Kühberger, C. (2009). Unterricht planen: Von der Jahres- zur Stundenplanung im Fach „Geschichte und Sozialkunde/Politische Bildung“. In Informationen zur Politischen Bildung. Forum Politische Bildung, Nr. 31., 31-38.

Arendt, H. (1973). The Origins of Totalitarianism, New York: Harcourt, Brace.

Austrian Federal Law (2008), Regulation Nr. 290. Bundesgesetzblatt für die Republik Österreich, Jahrgang 2008, 290. Verordnung

Banfield-Mumb, A., \& Mayrhofer, P. (2010). PoliPedia.at : Eine Online-Enzyklopädie von und für Jugendliche. In I. Ausserer, \& M. Haupt, \& P. Hladschik, \& S. Steiniger (Eds.), Lexika im Unterricht der Politische Bildung. Retrieved September 2nd, 2010 from: http://www.politik-lernen.at/site/shop detail.siteswift?so=all\& do=all\&c=download\&d=shop.item\%3A105541\%3A2

Beisswenger, A. (2010). Youtube und seine Kinder: Wie online-video, web tv und social media die Kommunikation von Marken, Medien und Menschen revolutionieren, Baden-Baden: Nomos Verlagsgesellschaft.

Bucy, E., \& Gregson, K. (2001). Media Participation: A Legitimizing Mechanism of Mass Democracy. In New Media \& Society, Vol3(3), 357-380.

Castells, M. (2000). The rise of the network society, Oxford, Blackwell Publishing.

Coleman, S. (2007). E-Democracy: The History and Future of an Idea. In R. Mansell \& C. Avgerou \& D. Quah \& R. Silverstone. (Eds.) The Oxford Handbook of Information and Communication Technologies, Oxford: Oxford University Press, 362-382.

European Commission (2010). A Digital Agenda for Europe. Retrieved September 1, 2010, from http:/leur-lex.europa.eu ILexUriServ/LexUriServ.do?uri=COM:2010:0245:FIN:EN:HTML

Department of Constitutional Affairs, United Kingdom (2007). The Future of Citizenship. Retrieved July 14, 2010, from http://www.dca.gov.uk/elections/pdfs/future-of-citizenship.pdf

Diendorfer, G., \& Mayrhofer, P. (2009). Arbeiten auf der wiki-Plattform PoliPedia.at zum Thema Grund- und Menschenrechte. In H. Ammerer \& R. Krammer \& E. Windischbauer. (Eds.) Politische Bildung konkret: Beispiele für kompetenzorientierten Unterricht. Zentrum Polis - Politik Lernen in der Schule: Wien, 64-69.

Diendorfer, G., \& Maier-Rabler, U., \& Parycek, P. (Eds.) (2010). Internetkompetenz von SchülerInnen. Aktivitätstypen, Themeninteressen und Rechercheverhalten in der 8. Schulstufe in Österreich, Forschungsbericht, Wien, Salzburg, Krems.

Escher, T. (2010). Wi(e)der die "üblichen Verdächtigen"? Politische Beteiligung via Internet. In J. Wolling \& M. Seifert \& M. Emmer. (Eds) Politik 2.0? : Die Wirkung computervermittelter Kommunikation auf den politischen Prozess. BadenBaden: Nomos Verlagsgesellschaft, 131-150.

Fuchs, C., \& Bernhaupt, R., \& Hartwig, C., \& Kramer, M.A., \& Maier-Rabler, U. (2006). Broadening eParticipation : Rethinking ICTs and Participation. In ICT\&S Center Research Paper Series 2. ISSN 1990-8563. Salzburg: ICT\&S Center. Retrieved September 19, 2010 from http://www.icts.sbg.ac.at/media/pdf/pdf1131.pdf

Fuchs, C. \& Obrist, M. (2010). Design principles for a Participatory, Co-operative, Sustainable Information Society (PCSIS). In $\mathrm{HCl}$ and society: Towards a typology of universal design principles. International Journal of Human-Computer Interaction, Volume 26 Issue 6, 638-656.

Green, J. \& Chambers, W. (2007) The Politics of Participation in Sustainable Development Governance, Tokio: United Nations University Press

Jenkins, H. \& Clinton, K. \& Purushotma, R. \& Robison, A. \& Weigel, M. (2006). Confronting the Challenges of Participatory Culture : Media Education for the 21st Century. Retrieved July 14, 2010, from http://www.newmedialiteracies.org/files/working/NMLWhitePaper.pdf

Kann, M. \& Berry, J. \& Gant, C. \& Zager, P. (2007). The Internet and youth political participation. In First Monday, Volume 12, Number 8. Retrieved September 19, 2010, from http://firstmonday.org/issues/issue12 8/kann/index.html 
Krammer, R. (2008). Kompetenzen durch Politische Bildung: Ein Kompetenz-Strukturmodell. In Kompetenzorientierte Politische Bildung, Vol. 29, Forum Politische Bildung: Innsbruck-Bozen-Wien, 5-14.

Livingstone, S. (2009). Youthful Experts? A Critical Appraisal of Children's Emerging Internet Literacy. In The Oxford Handbook of Information and Communication Technologies (pp. 494-513). Oxford: Oxford University Press.

Lupia, A., \& McCuppin, M. (1998). The Democratic Dilemma. Cited in Lutz G. (2006). Participation, Information and Democracy: The Consequences of Low Levels of Participation and Information for the Functioning of Democracy, Hamburg: Lit.

Lutz, G. (2006). Participation, information and democracy: The Consequences of Low Levels of Participation and Information for the Functioning of Democracy, Hamburg: Lit.

Maier-Rabler, U. (2006). Reconceptualizing e-Policy. Cultural Aspects and Digital Divide in Europe. In Sarikakis, K. \& Thussu, D. (Eds). Ideology of the Internet. Cresskill, NJ: Hampton Press, 195-212.

Maier-Rabler, U. \& Hartwig, C. (2007). ePartizipation - „Jugend aktiv“. Endbericht.

Maier-Rabler, U. \& Neumayer, C. (2009). E-Participation for Political Education: Challenges and Opportunities. In Electronic Participation, Lecture Notes in Computer Science, Volume 5694, Berlin, Heidelberg: Springer, 56-66.

Maier, E. \& Reimer, U. (2010). Process Support for Increasing Participation in eParticipation. In eJournal of eDemocracy and Open Government, Vol. 2., Number 1, 46-55.

Mansell, R. \& Avgerou, C. \& Quah, D. \& Silverstone, R. (2009). The Oxford Handbook of Information and Communication Technologies, Oxford: Oxford University Press.

Margetts, H. (2009). Public management change and e-government : The emergence of digital-era governance. In A. Chadwick \& P. Howard (Eds.). Routledge Handbook of Internet Politics (pp. 119-131). London, New York: Routledge.

Mesch, G. (2010). Wired youth: the social world of adolescence in the information age. London: Routledge.

Pateman, C. (1970). Participation and democratic theory. Cambridge: Cambridge Univ. Press.

Paus-Hasebrink, I. (2004). Neue Kinder - Neue Kindheiten? Zur Orientierung Heranwachsender in medialen Netzwerken. Perspektiven aus der Kindheits- und Jugendforschung. In M. Große-Loheide \& U. Hasebrink (Eds.). Netzwerke für die Informationsgesellschaft, Schriften zur Medienpädagogik, Bd. 36, Bielefeld: AJZ-Druck \& Verlag, 22-31.

Petrik, K. (2010). Deliberation and Collaboration in the Policy Process: A Web 2.0 approach. In: eJournal of eDemocracy and Open Government, Vol. 2., Number 1, 18-27.

Prensky, M. (2001). Digital Natives, Digital Immigrants. In On the Horizon, Vol. 9, Nr. 5, NCB University Press. Retrieved September 16, 2010 from: http://web.me.com/nancyoung/visual literacy/site map and resources files/Digital Natives Digital Immigrants.pdf

Putnam, R. (2000). Bowling Alone: The Collapse and Revival of American Community, New York: Simon \& Schuster.

Rheingold, H. (2000). The Virtual Community; electronic version. Retrieved July 14, 2010, from http://www.rheingold.com/vc/book/intro.html

Rheingold, H. (2006). The Pedagogy of Civic Participation. Retrieved July 14, 2010, from http://sl.nmc.org/wiki/Rheingold Presentation

Sen, A. (1999). Development as Freedom, Oxford: Oxford University Press.

Sen, A. (2009). The Idea of Justice, Cambridge: Harvard University Press.

Skidmore, P. \& Bound, K. (2008). The Everyday Democracy Index, London: Demos.

Tapscott, D. (1995). The Digital Economy in the New Network Economy: Promise and Peril in the Age of Networked Intelligence. New York: Mcgraw-Hill.

Toffler, A. (1980). The Third Wave, New York: Morrow.

Turner, F. (2005). Where the Counterculture Met the New Economy : The WELL and the Origins of Virtual Community. In Technology and Culture, Volume 46, Number 3, 485-512.

United Nations University (2007). The Politics of Participation in Sustainable Development Governance. Retrieved July 20, 2010, from http://www.unu.edu/unupress/2006/politicsofparticipation.html

Wiklung, H. (2005). A Habermasian analysis of the deliberative-democratic potential of ICT-enabled services in Swedish municipalities. In new media \& society, Vol7(2), 247-270,

Windischbauer, E. (2008). Probehandeln in Simulationsspielen. In Kompetenzorientiere Politische Bildung. Vol. 29, Forum Politische Bildung: Innsbruck-Bozen-Wien, 69-73.

\section{About the Authors}

\section{Ursula Maier-Rabler}

Ursula Maier-Rabler is the academic director of the interdisciplinary "Center for advanced research and studies in information and communication technologies and society" (ICT\&S Center) at the University of Salzburg, Austria. Besides her basic research interest in the Internet and digital networks, and their interrelationship with society, issues like e-democracy 
and e-participation, eLearning and cultures of information and communication are in the center of her focus. Current e-policy research, in particular comparative studies on ICT-policies of European Member States, attempt to identify different policy practices and introduce a culturally sensitive e-policy model

\section{Stefan Huber}

Stefan Huber is a doctoral researcher at the ePolicy \& eSociety Unit of the ICT\&S Center at Salzburg University. He obtained an MA in political science at Salzburg University and the CEP of the Institut d'Etudes Politiques (IEP) de Rennes, France. His research interest is focused on citizen deliberation, (e)-participation, political education, and participatory budgeting supported by ICTs. 